$$
\text { 사비교정술 }
$$

부산대학교 의과대학 이비인후과학교실

노 환 중·이 현 순

\title{
Surgical Management of Crooked Nose
}

Hwan Jung Roh, MD and Hyun Soon Lee, MD

Department of Otorhinolaryngology, College of Medicine, Busan National University, Busan, Korea

사비교정은 비성형술중에서 가장 어려운 문제이다. 골 부(bony vault) 를 절골하고 연골을 조작하여 재정렬시 키고, 필요하다면 융비술, 곡비축소술 또는 비첨까지 교 정해야 목적을 달성할 수 있기 때문이다. 따라서 미용적 이고 기능적으로 완전한 사비교정을 위하여는 비중격 성형술, 절골술, 이식술(graft), 제거술 등 비성형술에 필 요한 기본 술식을 철저히 알아야 하며, 이를 바탕으로 개개 환자마다 만나는 다양한 해부학적 변형에 대하여 응용할 수 있어야 한다.

\section{사비교정에 필요한 해부학적 고찰}

외비(nasal vault) 의 상부(upper) $1 / 3$ 은 골(bone) 로 서 구성되어 있고, 하부(lower) $2 / 3$ 는 연골로 지지되어 있다. 상부 $1 / 3$ 과 하부 $2 / 3$ 을 구성하는 조직의 차이는 사비교정에 각각 다른 방법이 적용되어야 함을 의미한다. 즉, 상부 $1 / 3$ 의 교정에는 절골술( osteotomy) 이나 rasp과 같은 bony work가 필요하고, 하부 $2 \beta$ 의 교정에는 연골과 연부 조직의 조작이 필요하다.

특히 하부 $2 / 3$ 에 대하여 외형적인 곧은 모양을 유지 하고 기능적 비폐색을 담당하는 것은 비중격연골이다. 따 라서 비중격연골의 조작시 rhinion에서 posterior septal

교신저자 : 노환중, 602- 739 부산광역시 서구 아미동 1가 부산대학교 의과대학 이비인후과학교실

전화 : (051) 240- 7333. 전송 : (051) 246- 8668

E- mail : rohhj@pusan.ac.kr angle 사이가 반드시 연속적이고 곧은 모양을 유지해야 한다. 즉 비중격연골의 dorsal과 caudal을 구성하는 Lshaped strut는 반드시 곧고, 폭 $1.5 \mathrm{~cm}$ 유지시키는 방향 으로 진행되어야 한다. 만일 L- shaped strut가 불안정 하고 만곡교정이 되어 있지 않으면 하부 $2 / 3$ 의 지지는 절대 이룰 수 없고 따라서 사비교정은 불완전하게 될 수밖에 없다. 또한 연골은 inherent memory를 갖고 원 래의 사비(deviated state) 를 유지하려는 경향이 있으므로 L- shaped strut가 가진 memory 를 절개술을 통하여 차단시켜야 한다. 그리고 L- shaped strut의 integrity 와 이와 연결된 지지 구조물인 상비익연골(upper lateral cartilage, ULC) 과 하비익연골(lower lateral cartilage, $\mathrm{LLC})$ 은 반드시 재구성되고 강화(strengthen) 되어야 한다.

\section{Bony(upper 1/3) Vault의 교정}

외비의 골부(bony nasal vault) 를 중심(midline) 으로 이동하기전에 dorsal profile을 술 전에 분석하여야 한다. 곡비(hump) 가 있으면 얼마나 교정하여야 할 것인지, 심한 사비로 비골의 많은 불균형이 있으면 외측 절골술을 한 번으로만 교정될 것인지, 안비(saddle)가 있으면 하부 $2 / 3$ 와 연계하여 전체적으로 얼마나 융비(augmentation) 를 할 것인지 등을 술 전에 계획해야 한다.

곡비 제거술(Hump reduction)

Hump의 제거는 우선 수술 전 제거해야 할 부위에 대한 


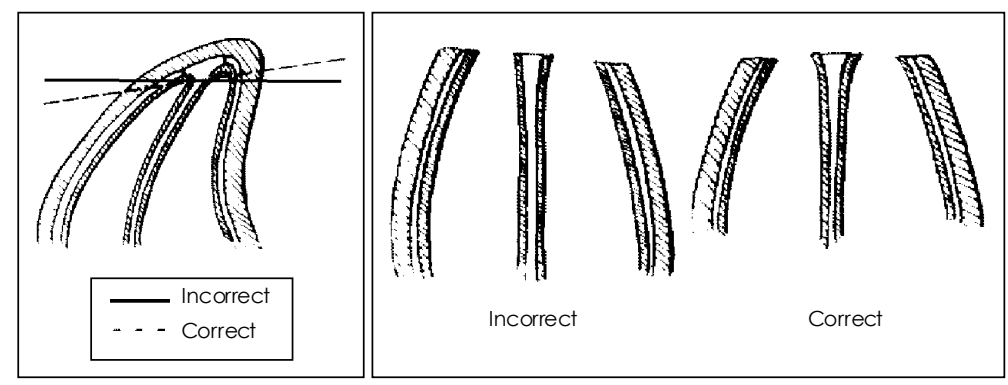

Fig. 1. A : When performing dorsal hump removal in a crooked nose, the Rubin osteotome may need to be advanced in a tangential plane to prevent over-resection of the more vertically oriented nasal bone. The broken-line pattern indicates the correct line of resection. B : Position and height of nasal bones

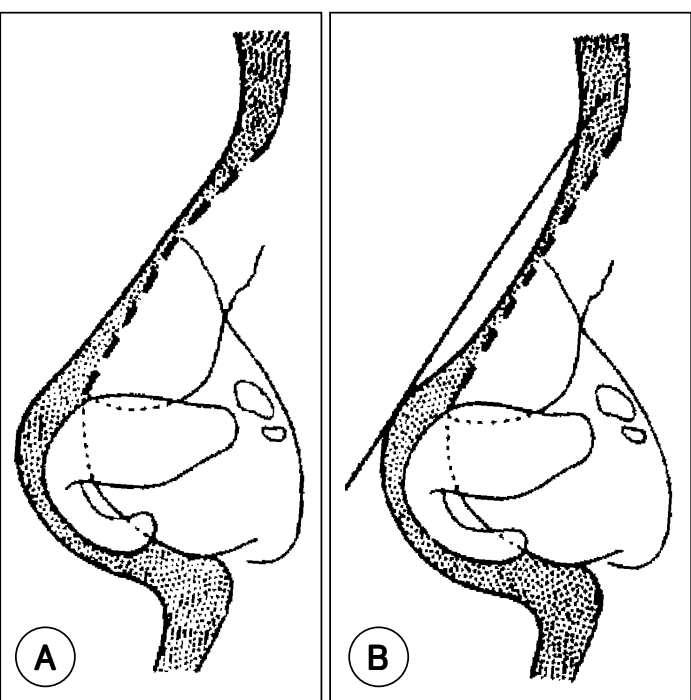

Fig. 2. The soft tissue and skin are thinner at rhinion area than around nasal tip and nasion. It is helpful to remove the hump less for straight dorsum( $A$ ), and to excise as straightway for a little depressed dorsum( $B)$.

대략적인 계획을 세운 후 연골막위 골막아래를 수술면 (surgical plane)으로 하여 노출시킨다. 대개의 hump는 연골- 골의 접합부위에 있으므로 15번 blade를 이용하여 연골부위의 절제를 시작한다. 연골부위는 탄성을 가지므로 osteotome만을 사용할 경우 완전한 절제가 어렵고, 절제 전에 비강측의 점막- 연골막(mucoperichondrium) 은 분 리가 되어 있어야 한다. 골부는 osteotome을 사용하여 절제된 연골부위와 합하여 en- bloc으로 제거한다. 이때 만곡(deviation) 된 쪽의 비골은 반대쪽보다 적게 제거하는 것이 좋다Fig. 1). 비배부는 코끝과 비근점(nasion) 부위의 연조직이 두껍고 rhinion 부위의 피부가 얇다. 또한 비근점으로 갈수록 비골의 두께가 두꺼우므로 hump 부위가 너무 많이 제거되고 비근점 부위가 적게 제거될

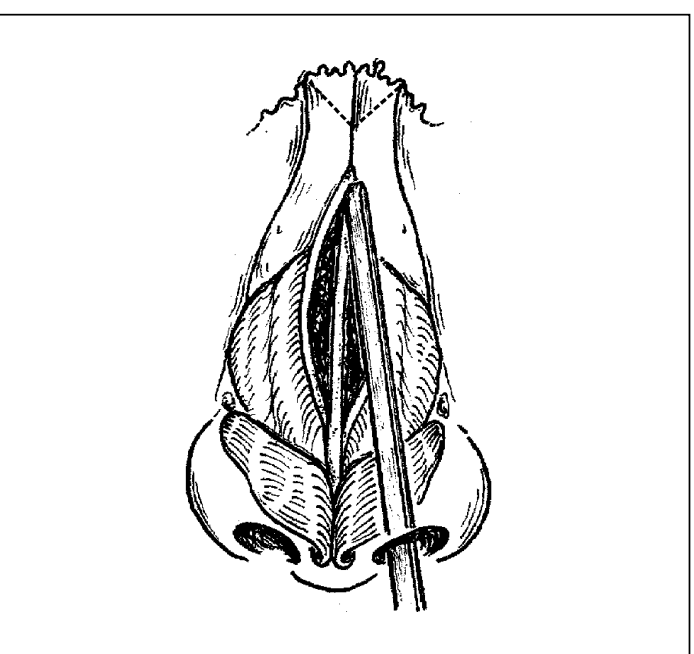

Fig. 3. Fading medial osteotomies. Place an osteotome flat against the septum with the edge facing laterally. Control the sharp leading edge of the chisel, as it moves under the skin, with te forefinger of the nondominant hand. Aboid the thick frontal bone.

가능성이 있다. 그러나 개인적인 선호도의 차이는 따라 rhinion 부위의 피부가 얇으므로 곧은 비배부를 만들기 위해서는 rhinion 부위를 약간 적게 제거하는 것이 좋고, 비배부가 약간 저하된 것을 선호하면 hump를 직선으로 제거한다( Fig. 2) .

\section{내측절골술(Medical osteotomy)}

먼저 ULC와 비중격을 분리시킨 후에, 내측절골술은 3 $\mathrm{mm}$ 또는 $4 \mathrm{~mm}$ 폭의 straight guarded osteotome을 비중격과 비골 접합부에 삽입하여 two- tap technique 으로 상부로 진행하면서 전두골에 도달하기 전에 외측 으로 진행한다(fading medial osteotomy, Fig. 3). 이때 너무 윗쪽으로 절골술을 시행할 경우 절골된 양쪽 비골 
을 오무릴때에 비근점부위의 뼈가 지렛대처럼 작용하여 절골된 뼈가 돌출되어 피부밖에서 만져질 수 있는" rocker deformity"가 생길 수 있으므로 주의하여야 한다.

\section{외측절골술(Lateral osteotomy)}

외측절골을 할 표식을 주사를 놓기 전에 피부에 미리 하면 절골술에 따른 위험을 피할 수 있다(Fig. 4). 3 $\mathrm{mm}$ 내지 $4 \mathrm{~mm}$ ostetome을 사용하여 이상와(pyriform aperature) 의 상부 3 4 mm 즉, 하비갑개 상부 부착부에서 시작하여 inner canthus의 내측을 향하여 후상방을 진행한다(high- to- low path). 이렇게 되면 이상와 base에 작은 triangular bone이 떨어지지 않고 보존되므로 하비갑개가 내측으로 변위( displace)가 되지 않는다. two- tap technique으로 osteotome의 cutting edge를 nondominant hand의 손가락으로 잘 조절하면서 inner canthus의 내측을 지나고 nasion을 향하게 되면 전체적으로 high- low- high path가 된다(Fig. 5). 이렇게 되면 bony vault는 비강측(inward) 으로 절골이 되어 controlled backfracture가 된다. 필요하면 thumb pressure로서 골절을 완전하게 한다. 외측절골이 지나갈 부위에

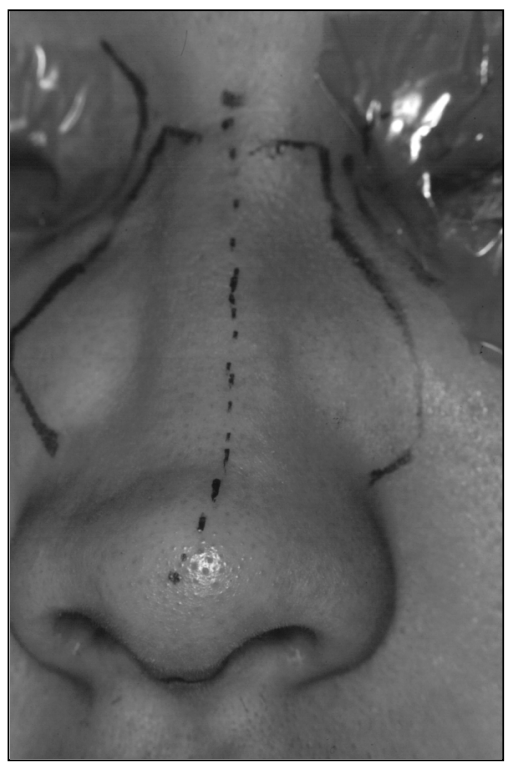

Fig. 4. It is helpful to mark the proposed line of the lateral osteotomy on the skin preoperatively to reduce the risk of osteotomy-induced complications. subperiosteal tunnel을 만들 것을 권장하기도 하나 저자는 굳이 하지 않는다.

외측절골술시 흔히 누관 손상의 위험을 우려한다. 누관의 전장에 있어서 가장 위험한 부위는 골에 의해 싸여있지 않은 $10 \mathrm{~mm}$ 정도의 안와의 내하측부위이다. 또한 medial canthal ligaments $(\mathrm{MCL})$ 는 누관을 싸고 안와의 내측 으로 $3 \mathrm{~mm}$ 정도 올라와 부착되어 있다. 그러므로 너무 외측으로 치우친 low lateral osteotomy 인 경우 누관이나 $\mathrm{MCL}$ 의 손상이 올 수 있으므로 외측절골의 path를 피부에 표시할 때 inner canthus에서 최소 $3 \mathrm{~mm}$ 내측으로 표시한다. 반대로 누관 손상에 대한 지나친 우려로 너무 내측으로 치우친 절골술을 시행하면 사비의 완전한 교정이 이루어지지 않고 계단모양의 변형이 피부를 통하여 느껴 지거나 투시될 수 있다. 외측절골의 시작이 하비갑개 상부 부착부위가 아니라 너무 아랫쪽에서 시작되면 술후 하비 갑개가 내측으로 편위되어 코막힘의 원인이 될 수 있다. 따라서 외측절골술은 하비갑개의 부착부위에서 시작하여 안와의 내하방에서 약 $3 \mathrm{~mm}$ 정도를 띄운 후 비근점 부 위에서 끝내는 것이 무난하다.

내외측절골술을 마치면 bony vault는 완전히 움직일 수 있어 중심(midline) 으로 이동할 수 있어야 한다. 이때

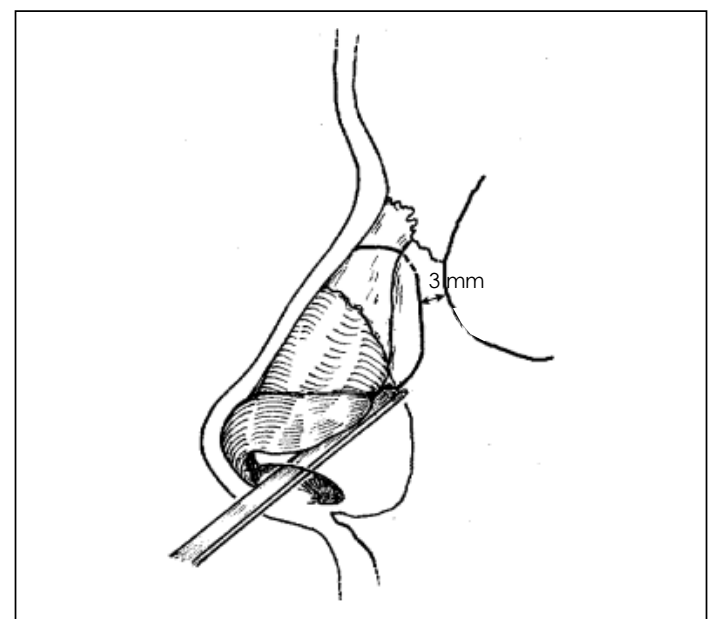

Fig. 5. Lateral osteotomies should be started from a point $3 \mathrm{~mm}$ to $4 \mathrm{~mm}$ above the base of the pyriform aperture to a point adjacent to the inner canthus of the eye. Some rhinoplasty surgeons find it helpful to mark the proposed line of the osteotomy on the skin before executing this maneuver. 
비중격의 골부의 심한 만곡으로 절골된 비골을 중심으로 이동할 수 없으면 bony septum을 blade handle이나 Walsham forcep으로 움직여서 절골된 비골과 함께 중 심으로 이동시킨다. 만일 절골술이 불완전하여 greenstick fracture가 일어나면 술후에 조직의 memory 로 인하여 bony vault는 다시 만곡된다. 60대 이상의 노령 환자에서는 어느 정도 greenstick fracture가 허용되나, 저자의 경우 greenstick fracture가 일어나면 $2 \mathrm{~mm}$ transcutaneous osteotome을 이용하여 비골의 완전골 절(backfracture and infracture)을 완성한다. 또한 곡 비교정을 위한 hump 제거 후 외측절골이 완전히 이루 어지지 않으면 open roof deformity 가 남을 수 있다.

\section{Double osteotomy}

심한 사비로 인하여 비골의 convexity나 concavity 가 과도한 경우 한 개 이상의 외측절골술이 필요하며 여기에는 술자의 선호도에 따라 intermediate osteotomy, vertical lateral osteotomy, multiple lateral osteotomy 가 있다. 저자의 경우 술전 계획상 한 번 이상의 외측절골술이 필요한 경우 $2 \mathrm{~mm}$ transcutaneous osteotome으로 비골의 convex side에 intermediate osteotomy 를 하고 마지막으로 외측절골술을 시행하는 방법을 선호한다.

\section{Cartilagenous(lower 2/3) Vault의 교정}

Vault의 upper $1 / 3$ 은 골부이므로 곡비축소술(hump reduction)이나 내, 외측 절골술과 같은 bone work로서 교정이 가능하다. 그러나 bony vault의 교정후에 lower $2 / 3$ 의 교정이 없다면 사비는 다시 원 위치로 돌아간다. lower $2 / 3$ 의 중심은 비중격연골이며 상비익연골(ULC)
와 하비익연골(LLC)이 연결되어 있다. 따라서 vault의 lower $2 / 3$ 는 만곡된 비중격의 교정 없이는 전체적인 사비교정은 불가능하다. 이러한 원칙은 간결하게“ As the septum goes, so goes the nose" 란 말로 표현할 수 있다(Beekhuis, 1973). 그러므로 사비 치료에서의 첫 단계는 휘어진 비중격을 바로 펴는 것(straightening) 이며 이것이 이루어지지 않으면 곧은 외비도 이루어 질 수 없다. 또한 사비는 비중격 만곡으로 인한 외비의 만곡 뿐만 아니라 기능적으로 비폐색을 초래하기 때문에 비중격의 완벽한 교정만이 기능적 그리고 성형적 목적을 달성 할 수 있다.

\section{Dorsal septum의 처리}

사비 교정시의 비중격의 분리 및 조작은 open approach를 통하여 두 방향 즉 비배부의 연조직 거상을 통하여 위(above)에서, hemitransfixion incision 또는 양측 medial crura의 분리와 비중격선단을 통해 아래 (below)에서 직접 시야하에 시행하는 것이 추천된다 (Fig. 6A).

$\mathrm{ULC}$ 와 비중격의 분리는 비중격선단의 절개를 통하여 양측 subperichondrial flap을 비중격과 ULC가 만나는 부위까지 올린 다음, Freer elevator를 이용하여 양측 subperichondrial tunnel을 통하여 비내 점막(intranasal mucosa)을 violating 하지않고 직접 시야하에 비중 격을 ULC로부터 분리한다(Fig. 6B). 반대편의 경우 앞의 방법과 같이 하던지 또는 위에서 D- knife와 elevator 로서 바로 ULC와 비중격을 분리하고 비내점막을 분리, 보존한다(Fig. 6C). 만일 비내 점막을 보존하지 않으면 ULC의 inferior-medial collapse가 일어나 nasal valve area의 단면적 감소를 초래하므로 술후 비폐색이
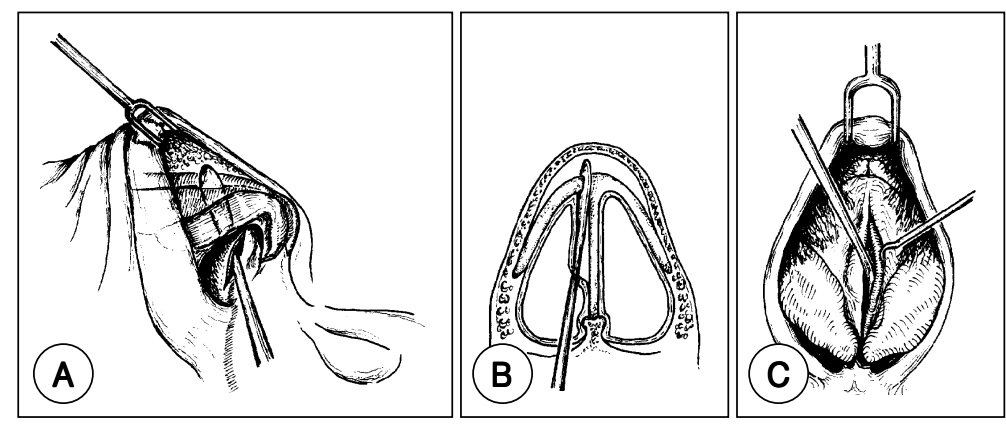

Fig. 6. Division of the upper lateral cartilages from their attachment to the dorsal septum in the submucoperichondrial plane. Great care should be taken to preserve an intact mucoperichondrium. 


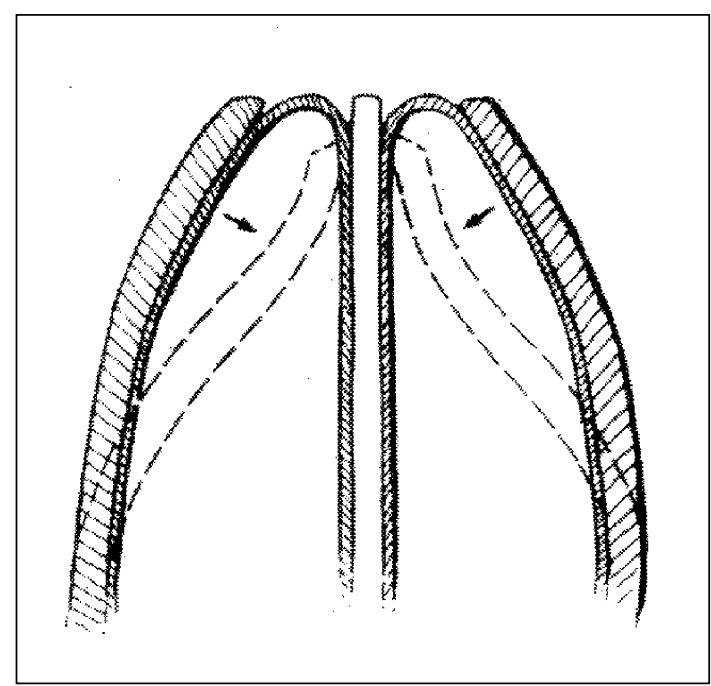

Fig. 7. When the upper lateral cartilages are divided form the nasal septum, the upper lateral carilages can collapes inferomedially, resulting in compromise of nasal valve function.

생길 수 있다. 보존된 비내점막은 ULC를 지지하고 이 탈을 방지함으로서 술 후 nasal valvular collapse를 방지한다Fig. 7). ULC와 비중격의 분리후에 비중격 연골의 concave side에 절개선를 가하여 연골이 가진 inherent memory 를 차단하지 않으면 술전 사비와 같은 위치로 다시 만곡이 된다" The crooked nose has a memory").

비중격이 ULC로부터 분리되면 L- shaped septal strut의 dorsal segment의 실제적인 만곡 정도를 파악 한다. 경도의 만곡 정도는 내, 외측절골술후에 비교적 쉽게 중앙으로 옮길 수 있으며, ULC는 anterior septal angle 근처의 비중격에 봉합 고정한다.

비중격 연골의 전체적인 만곡 혹은 L- shaped septal strut 중 caual segmente의 심한 변형으로 인하여 dorsal segment가 같이 심하게 만곡된 경우는 다양한 선택을 두어 교정할 수 있다(T able 1).

가장 흔한 것이 편측의 concavity와 반대측의 convexity 가 있는 C- shaped deformity 인 경우이다. 비중 격선단이 중앙에 있거나 만일 그렇지 않다면 비중격선 단을 중앙에 위치하게 조작한 후에 camouflaging technique을 사용하여 비배부의 곧은 모양(straight appe-
Table 1. Surgical options for correction of cartilaginous vault

1. Dorsal septal deformity

Minor C- or S-shaped deformity

Cut on concave septum

Spreader graft

Camouflaging augmentation

Significant C- or S-shaped deformity

Full-thickness cut on septum

Shaving convex side, unilateral

Spreader graft, unilateral

Onlay graft on ULC

Bilateral spreader graft

Ethmoid bone stenting sandwich graft

Extracoporeal septoplasty : subtotal septal reconstruction

Camouflaging augmentation

2. Caudal septal deviation

Subluxation

Fracture of anterior nasal spine with crest

Resection of posterior septal angle

Swing back and fixation to contralateral side

Subtotal septal reconstruction

arance) 을 얻을 수 있다. 즉, 비중격 convex dorsal border는 shaving하여 convex prominence를 줄임과 동시에 concave dorsal border는 ULC와의 사이에 비중 격연골에서 얻은 spreader graft를 삽입하고 5- 0 PDS mattress suture로서 고정함으로서 concavity 를 없애고 nasal valve area의 단면적도 보강할 수 있다(Fig. 8). 그런 다음 skin을 redrap하여 변형정도를 다시 검사하 고 만일 residual concavity 가 존재하면 concave side에 있는 ULC위에 onlay graft를 할 수 있다.

C- shaped deformity 가 전체적으로 길고 심하거나 S- shaped deformity가 있다면 concave septum에 절개선을 넣은 후에 사골수직판을 $5 \sim 12 \mathrm{~mm}$ (길이), 3 5 mm(폭) 의 사각모양으로 조각하여 비중격 dorsal border 의 양측에 대고 4- O PDS mattress suture로서 고정하는 ethmoid bone stenting graft를 하거나, 양 측에 비중격연골을 1 4 $\mathrm{mm}$ (두께), 3 $6 \mathrm{~mm}$ (폭) 의 사 각모양으로 하여 spreader graft로서 양측에 대어 비중 격의 dorsal border를 펴게 할 수 있다. 만일 이것으로 

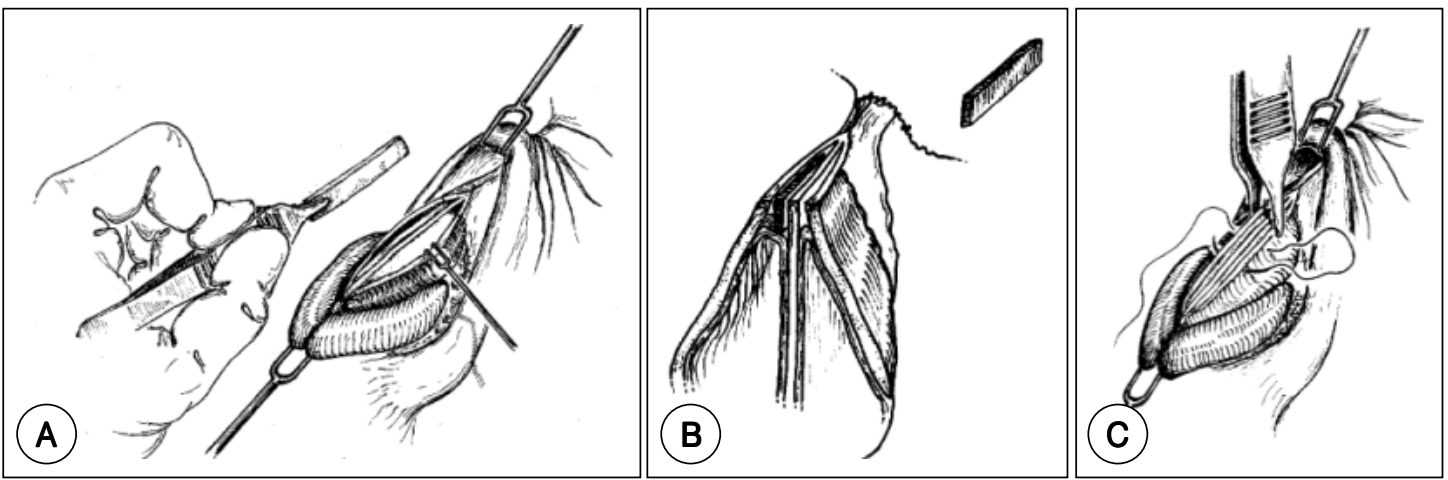

Fig. 8. A spreader grafts are placed into a pocket between upper lateral cartilage and dorsal septum. A typical graft extends from the osteocartilaginous junction to the anterior septal angle. B : Bilateral spreader grafts in submucoperichondrial pocket between upper lateral cartilage and septum. C : Spreader grafts sutured into position. Several horizontal mattress sutures secure the spreader grafts and upper lateral cartilages. A needle of adequate size(such as a PS-2) facilitates engaging all structures( Upper lateral cartillage-to-spreader graft-to-septum-to-spreader graft-toupper lateral cartillage) in a single pass. Note how this suture passes through the dorsal edge of the upper lateral cartilage.

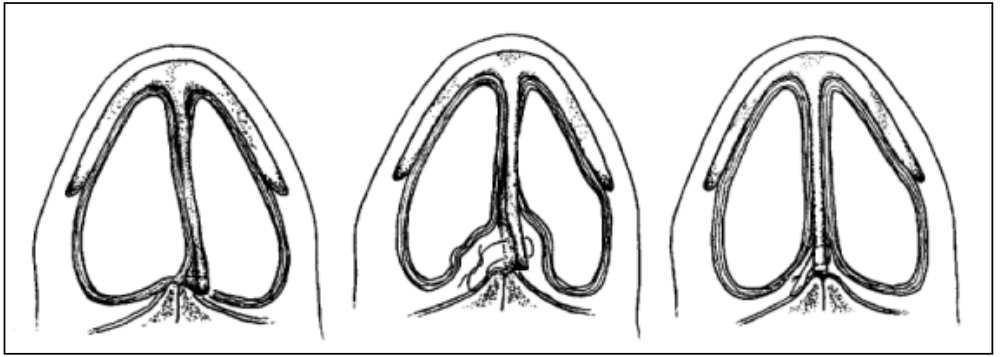

Fig. 9. Deviated caudal septum, "swinging door" maneuver.

불충분하고 술후 약간의 안비가 우려되면 augmentation 으로 곧은 비배부를 얻을 수 있다. 모든 camouflage graft가 위치한 후에는 ULC의 anterocaudal portion과 septum의 anterior septal angle 근처 사이를 봉합하여 ULC가 inferomedial collapse 되는 것을 방지한다.

이러한 camouflage 방법은 전체적인 비중격연골 만 곡에 대하여 수술하지 않고서도 비배부를 곧게 보이게 하는 효과가 있으나 전제 조건은 비중격 만곡으로 인 하여 환자가 비폐색이 없어야 하며 만일 비폐색을 동반한 경우에는 비중격성형술을 실시하여 비중격 만곡 부위를 재정렬함으로써 비폐색을 같이 개선하여야 한다.

\section{Caudal septum의 처리}

비중격선단부(caudal septum : posterior septal angle) 는 외비의 lower 1/3을 지지하므로 대단히 중요 하다. 비중격선단부가 심하게 만곡되면 tip projection의
소실, over- rotated nose와 retracted columella 등을 초래한다.

비중격선단부가 nasal spine과 maxillary crest로 부 터 subluxation된 것과 같은 만곡일 경우 먼저 비중 격 연골의 오목면에 절개선(cross- hatch incision)을 가 하여 연골의 memory 를 없앤 다음, posterior septal angle 부분을 작은 삼각형 모양으로 제거하여 비중격선 단이 중앙으로 swing back할 수 있게 한 후에 반대편 nasal spine의 periosteum에 봉합함으로서 비중격선 단을 중앙에 고정할 수 있다(swinging door maneuver, Fig. 9).

\section{Subtotal septal reconstruction}

Posterior septal angle, anterior septal angle 및 L- shaped septal strut전체가 골절되고 심하게 만곡된 경우에는 변형된 부위를 제거하고 곧게 된 연골로 치환 
함으로서 해결할 수 있다. 만곡이 없고 편편한 비중격을 지지부위가 아닌 posteroinferior portion으로부터 적어도 $1 \sim 1.5 \mathrm{~cm}$ 폭을 가지고 dorsal과 caudal segemnt를 대신할 수 있는 길이를 가진 연골을 채취하여 L- shaped piece로 조각하여 L- shaped septal strut 전체를 치환할 수 있다. 치환된 L- shaped septal strut는 골연골 결합부인 rhinion과 nasal spine에 반드시 봉합 고정하여야 하고, 만일 L- shaped septal strut의 caudal portion을 양측 medial crura 사이에 봉합하면 columellar strut처럼 작용하게 할 수 있다. 그런 다음 양측 mucoperichondrial flap과 L- shaped septal strut는 running mattress suture로서 고정하고 비내 septal splint로서 지지한다(subtoal septal replacement, Fig. 10).

자가 비중격연골이 흡수가 없고 휘어짐이 없으므로 이러한 방법은 만일 L- shaped strut할 만한 적당한 크 기의 연골을 비중격에서 채취할 수 없다면 적용하기가 어려우나, 불가피한 경우에는 늑골 연골을 사용한다.

\section{Spreader graft}

Spreader graft는 위장 이식(camouflage graft) 으로서 dorsal septum을 곧게 해 보이는 효과가 있을 뿐 아니라, 일종의 spacer로서 middle vault의 협소화 overnarrow) 나 internal valve의 collapse를 방지하는 것으로 사비 교정시에 대단히 유용하게 사용된다. 사비 교정시에 middle vault의 지지를 잃고 narrow middle vault와 internal nasal valve collapse를 초래하는 경우는 LLC lateral crura에 cephalic trim을 시행 한 뒤 ULC caudal margin과의 scroll 관계를 절단시킴으로서 발생할 수 있고, 또한 외측절골술후 ULC medialzation이 초래되어 생길 수 있다. 특히 술전에 이러한 경우가 잘 초래되는 고위험환자를 잘 파악해야한다. 이런 고위험환자를 일명 narrow- nose syndrome(Sheen, 1984) 이라고 하는데 특징은 short nasal bone, long weak ULC, thin skin, narrow projecting nose이다. 이런 환자는 ULC의 collapse가 잘 초래되므로 전술한 술식을 적용할 때 주 의를 요하고 spreader graft의 삽입이 도움이 된다.

방법은 비중격연골을 1 3 $\mathrm{mm}$ ( 두께) 와 3 $6 \mathrm{~mm}$ ( 폭) 의 사각모양으로 하여 rhinion에서 anterior septal

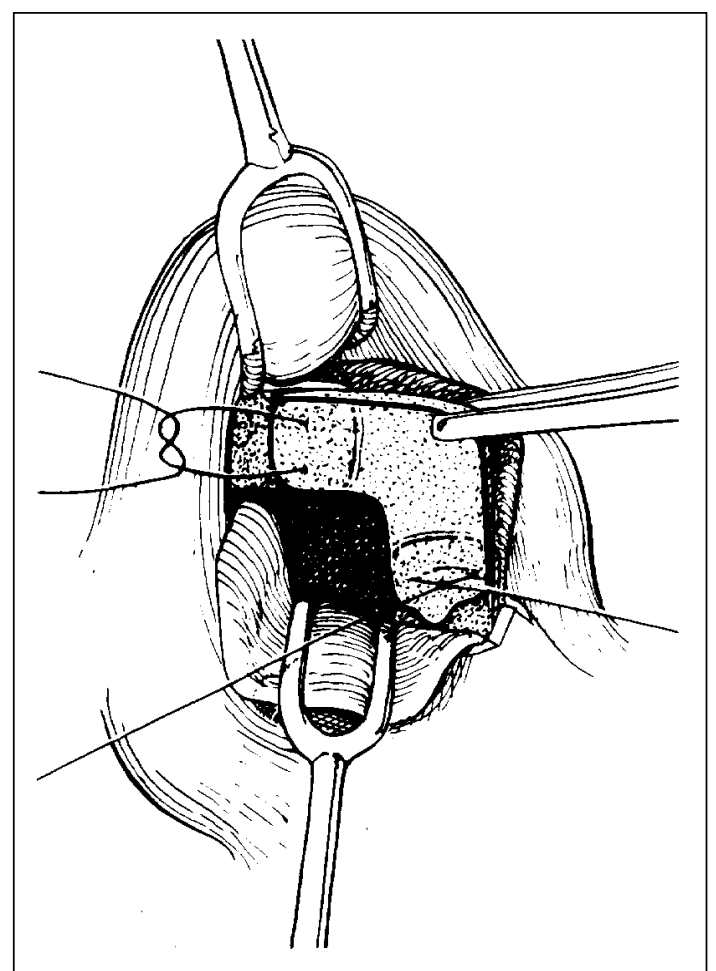

Fig. 10. Partial replacement of the septal L-shaped strut( anterior septal angle and caudal segment) with an autologous cartilage graft. The graft may be taken from the posteroinferior region of the nasal septum or from rib. Note how the graft is sutured to cartilage remnants at the osteocartilaginous junction and nasal spine (From Toriumi DM, Ries WR : Innovative surgical management of the crooked nose. Facial Plast Surg Clin North Am 1 : 6378, 1993.) .

angle까지 submucoperichondrial pocket에 삽입하고 5- O PDS로서 봉합 고정한다. 이때 ULC가 buckling되 지 않게 조심하여야 하며, spreader graft와 비중격을 봉 합한 뒤 다시 양측 ULC와 봉합할 수 있으나 저자는 양측 ULC, spreader 및 비중격을 모두 한꺼번에 mattress suture로서 고정하는 방법을 선호한대 Fig. 8). spreader graft 삽입 후에 middle vault를 직접 만져서 width와 symmetry 를 확인한다. middle vault의 width가 bony vault보다 넓어서는 안되고 nasal tip보다 좁아서는 안 된다. 술 후 시간이 지남에 따라 부종이 감소되고 scar contracture의 dy namics로 ULC가 내측으로 점점 당 겨지므로 좁아짐을 감안하여야 한다. 저자는 한국인의 연골 특성을 감안하여 너무 두꺼우면 overwidening을 
초래하므로 가능한 얇게 하는 것을 추천하나 이 역시 경험 을 요한다. 또한 환자의 상황에 따라 편측 또는 양측이 라도 서로 두께를 달리하여 삽입할 수 있다.

중심 단어 : 사비. 교정.

\section{REFERENCES}

1) 제 1 회 코성형술 워크샵; 1997 September 27-28; 인하대 학교 의과대학 이비인후과교실

2) 제 3 회 코성형술 워크샵; 1999 November 21-22; 안하대 학교 의과대학 이비인후과교실

3) 제 4 회 코성형술 워크샵; 2001 November 17-18; 인히대 학교 의과대학 이비인후과교실

4) Aiach G. Atlas of Rhinoplasty. St. Louis. Quality Medical Publishing, Inc.;1996.

5) Anderson JR. Straightening the crooked nose. Trans Am Acad Ophthalmol Otolaryngol 1972;76:938-45.

6) Beekhuis GJ. Nasal septoplasty. Otolaryngologic Clinics of North America 1973;6:693.

7) Brain D. The nasal septum. In:Kerr A.G, Mackay I.S, Bull T.R, editors. Scott-Brown's Otolaryngology. 6th ed. Oxford: Butterworth-Heinemann;1997. p.4/11/1-4/11/25.

8) Johns NS. Principles for correcting the septum in septorhinoplasty: two-point fixation. J Laryngol Otol 1999;113: 405-12.

9) McCollough EG. Nasal plastic surgery. In: The Crooked nose. Philadelphia; WB. Saunders;1994. p.235-45.

10) Murakami W, Wong L, Devidson J. Application of the biomedical behaviour of cartilage to nasal septoplastic sur- gery. Laryngoscope $1982 ; 92: 300-9$.

11) Rees TD. Surgical correction of the deviated nose. In:Rees TD, LaTrenta GS, editors. Aesthetic plastic Surgery. 2nd ed. Philadelphia: WB Saunders;1994. p.293-334.

12) Ridenour BD. The nasal septum.. In:Cummings C.W, Fredrickson JM, Harker LA, Krause CJ, Schuller DE, editors. Otolaryngology-Head and Neck Surgery. 3rd ed. St. Louis: St. Mosby Year Book;1993. p.921-48.

13) Sessions, RB, Wenig BL. The nasal septum. In: Krause CJ, editors Otolaryngology-Head and Neck Surgery. St. Louis: Mosby company;1986. p.672-97

14) Sheen JH. Spreader graft: A method of reconstructing the roof of the meddle nasal vault following rhinoplasty. Plast Reconst Surg 1984;73:230-7.

15) Tardy ME, Torilemi D. Nasal Reconstruction and Rhinoplasty. In: Ballenger J.J, Snow JB, editors. Otolaryngology Head and Neck Surgery. 15th ed. Baltimore: Williams \& Wilkins;1996. p.19-68.

16) Tardy, Jr ME. Rhinoplasty. Philadelphia: W.B. Saunders Co;1997. p.588-639.

17) Toriumi DM, Johnson CM Jr. The Crooked Nose. Operative Techniques in Otolaryngology-head and Neck Surgery 1990;1:252-4.

18) Toriumi DM, Ries WR. Innovative surgical management of the crooked nose. Facial Plast Surg Clin North AM 1993; 1:6378-82.

19) Wright K. Principles of nasal septum reconstruction. Trans Am Aca Ophthalmol Otolaryngol 1969;73:252-5.

20) Dean MT, Daniel GB. Rhinoplasty: Dissection Manual. Phildelphia. Lippincott Williams \& Wilkins;1999. 